\title{
History of innovations in oral and maxillofacial surgery
}

\author{
Kevin C. Lee ${ }^{1}$, Sung-Kiang Chuang ${ }^{2,3,4,5}$ \\ ${ }^{1}$ Division of Oral and Maxillofacial Surgery, New York-Presbyterian/Columbia University, Irving Medical Center, New York, NY, USA; ${ }^{2}$ Department \\ of Oral and Maxillofacial Surgery, University of Pennsylvania, School of Dental Medicine, Philadelphia, PA, USA; ${ }^{3}$ Brockton Oral and Maxillofacial \\ Surgery Inc., Brockton, MA, USA; ${ }^{4}$ Department of Oral and Maxillofacial Surgery, Good Samaritan Medical Center, Brockton, MA, USA; \\ ${ }^{5}$ Department of Oral and Maxillofacial Surgery, Kaohsiung Medical University, School of Dentistry, Kaohsiung \\ Contributions: (I) Conception and design: Both authors; (II) Administrative support: Both authors; (III) Provision of study materials or patients: None; \\ (IV) Collection and assembly of data: None; (V) Data analysis and interpretation: None; (VI) Manuscript writing: Both authors; (VII) Final approval \\ of manuscript: Both authors. \\ Correspondence to: Sung-Kiang Chuang, DMD, MD, DMSc. Department of Oral and Maxillofacial Surgery, University of Pennsylvania, School of \\ Dental Medicine, Philadelphia, PA, USA. Email: sungkiangchuang@gmail.com.
}

\begin{abstract}
Oral and maxillofacial surgery is a specialty that was born out of the individual efforts of surgeons trained in both medicine and dentistry. The specialty derived much of its early identity from its necessary role in management of head and neck trauma during World War I. Outpatient oral surgery was the mainstay of practice in the early to mid $20^{\text {th }}$ century. Office-based practice still composes the largest share of the workforce, however the landscape of community practice has transformed over the last decades with the advent of dental implants. Enthusiasm for maxillofacial repositioning osteotomies was introduced later and gave a new identity to the specialty. The management of oral cancerous lesions and head and neck pathology is a more recent phenomenon. Parallel improvements in technology have made elaborate reconstructions possible, and our surgeons are now leading the way in comprehensive functional maxillofacial restoration. The future of OMS remains bright as much of the guesswork used in prior iterations is now replaced with precision surgery in both major and minor surgical cases.
\end{abstract}

Keywords: History of oral surgery; anesthesia; craniofacial; reconstruction

Received: 06 March 2021; Accepted: 20 May 2021; Published: 10 March 2022.

doi: 10.21037/fomm-21-24

View this article at: http://dx.doi.org/10.21037/fomm-21-24

Oral and maxillofacial surgery (OMS) is the premier specialty for treating deformities and pathologies of the face and jaws. Modern OMS practitioners have further expanded the specialty's scope to include all processes spanning from the dura to the pleura. Nearly all seasoned OMS surgeons will agree that many of the procedures performed today were not available or even possible decades ago during the time of their training. With parallel advances in technology and engineering, OMS are able to apply these outside principles and tools to their daily practice and obtain improved patient outcomes. This spirit of innovation is and will continue to be integral for growth of our specialty. There are a handful of individuals who have paved the way for the work done by today's surgeons.

\section{The ancient practice of OMS}

The origins of dentistry likely date to prehistoric times as exodontia and dental remedies have been attempted as long as caries have been present. The origins of oral and maxillofacial surgery date back to ancient Egypt (2700 BCE) with the first written record of mandible fracture management using facial bandages (1). Like many specialty areas of medicine and surgery, the first practitioners of OMS were general physicians who treated head and neck complains alongside other systemic processes. Hippocrates, considered to be the father of modern medicine, advocated treating jaw fractures with interdental wires over facial bandages. He also documented a technique for reducing 
temporomandibular joint dislocations by applying pressure on the external oblique ridge, a technique that is still used by OMS providers today to reduce open lock jaw (2). Over time, a variety of invasive techniques for treating facial and odontogenic infections and abscesses were also developed largely out of necessity. These approaches to odontogenic infections were not created by OMS surgeons, but by general surgeons and physicians.

\section{OMS as a recognized specialty}

OMS has always been a specialty that lay at the interface of medicine and dentistry. The first text related to the maxillofacial specialty, Traités des dépôts dans le sinus maxillaire, des fractures, et des caries de l'une et l'autre machoire (Treatise on deposits in the maxillary sinus, fractures and caries of both jaws), was published by French dentist and surgeon Anselme Jourdain (3). Eighteen years after his first publication, Jourdain published arguably his more famous 2-volume text Traité des maladies et des opérations réellement chirurgicales de la bouche, et des parties qui y correspondent (Treatise on surgical diseases of the mouth) where he described and illustrated the detailed anatomy and diseases of both the upper and lower jaws. During the 1800 s in the United States, a group of individuals who were trained first as physicians and later as dentists began focusing their practice in what would be considered modern OMS. In 1849, Simon P. Hullihen, MD, DDS, a dental surgeon from West Virginia, and the first oral surgeon in the United States, published the first scientific paper on an orthognathic procedure in the American Fournal of Dental Science (1). In that case report, he performed a mandibular subapical osteotomy with bilateral wedge resections to correct a prognathic mandible. He would later go on to complete over 1,100 orthognathic procedures in his career and found the first hospital-based dental clinic. James E. Garretson, AM, MD, DDS was another early oral surgeon who through his contributions is largely regarded as the father of oral surgery. Appointed to a hospital position at the Hospital of the University of Pennsylvania, he advocated for oral surgery to become a specialty separate distinct from other disciplines in medicine and surgery.

In 1918, the American Society of Exodontists was first established by 29 dentists (4). Between 1918 and 1978, the organization underwent 3 name changes until it became what is today known as the American Association of Oral and Maxillofacial Surgeons (AAOMS). The founding years of the AAOMS also coincided with World War I (WWI).
At that time, dental surgeons were enlisted for the purposes of treating facial trauma (5). This role would later pay dividends, as it forced dental and OMS surgeons to develop an expertise in maxillofacial reconstruction. However, the influx of maxillofacial injuries that stemmed from the trench warfare required more than just frontline responders. In response, many nations developed maxillofacial injury units. Sir Harold Gillies established the first such unit in the British army and introduced a variety of techniques into the reconstructive toolbox most notably the tubed pedicle flap for closure of large soft tissue defects. Many OMS are familiar with the Gillies approach to the zygomatic arch that was named after the same surgeon as he first described the inconspicuous extraoral incision to access the fractured bony arch. In the United States, the wartime effort in treating head and neck injuries was led by Vilrary P. Blair who later included Robert H. Ivy, DDS, MD, under his mentorship as his personal surgical assistant (6). Robert Ivy, an OMS surgeon, gained tremendous clinical expertise in traumatic reconstruction, and one of his many contributions was the Ivy loop for intermaxillary fixation still used today. After his war service, Robert H. Ivy later established the first multidisciplinary team for treating cleft lip and palate deformities, a model for comprehensive that continues to be used (7).

\section{High-speed handpiece, anesthesia, and dental implants}

Third molar removal predates the introduction of the modern high-speed handpiece. Prior to the inception of motorized drills, impacted third molars were removed with mallets and chisels as originally described by Pell and Gregory. The lingual split technique, which involves removing the thinner lingual plate to allow for a lingual path of draw, was later presented. In 1964, Robert Hall, a Pittsburgh oral surgeon, introduced the first straight surgical high-speed handpiece (8). This device, known as the Hall drill, was powered by pressurized nitrogen and allowed users to cut through bone and tooth structure with more ease than the existing belt-driven low-speed contemporary alternatives. Although electric low-speed handpieces reaching up to 3,000 RPM had been on the market since the early $20^{\text {th }}$ century, it was not until much later that the air turbine was integrated into the design allowing these electric handpieces to reach useful surgical speeds in excess of 400,000 RPM.

Prior to the introduction of ether (Table 1), there 
Table 1 Timeline of landmark events in oral and maxillofacial surgery

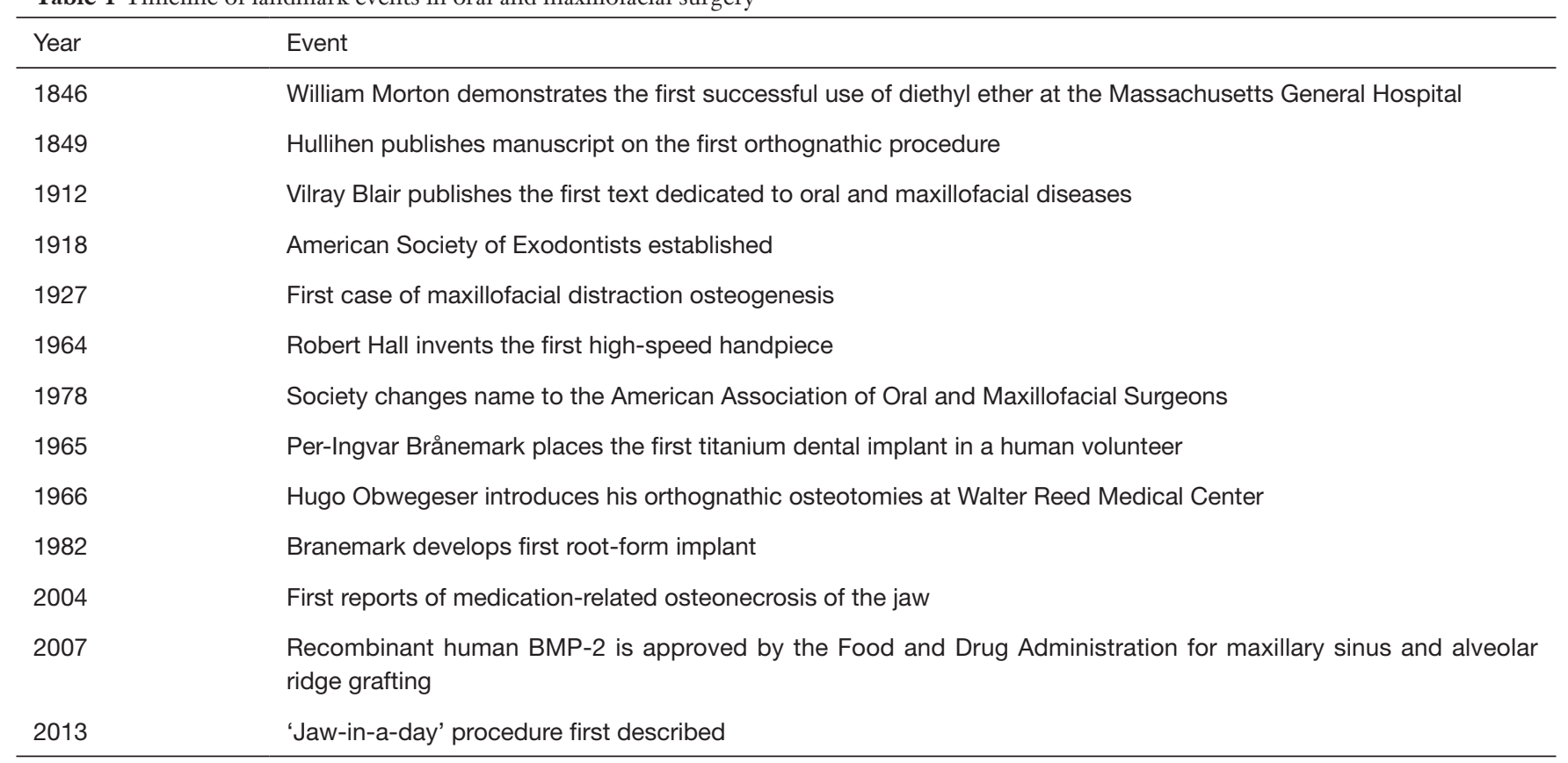

had been multiple failed attempts at developing general anesthetics using opium and other herbal substances. The advances in surgical technique demanded better means of anesthesia, as patients would routinely chose death over the inevitable pain of open surgery. It was not until William Morton, a dentist by training, publicly demonstrated the successful use of diethyl ether at the Massachusetts General hospital in 1846 for the purposes of dental extraction. A month later, the ether technique was successfully employed yet again to remove a benign tumor of the neck. Over the last century and a half, general anesthesia separated into its own field of expertise following the numerous contributions by anesthetists such as Sir Robert Macintosh and Paul Jansen. OMS surgeons continue to practice outpatient anesthesia as first demonstrated by Dr. Morton in the Ether Dome. Newer monitoring devices such as the wireless precordial stethoscope (9) and bispectral index monitor (10) are available to detects signs of over sedation before clinical symptoms are present. The safety of intravenous anesthetics agents administered by OMS has been proven multiple times over $(11,12)$.

The process of osteointegration was first discovered and replicated by Per-Ingvar Branemark, an orthopedic surgeon. After this breakthrough, Branemark placed the first titanium implant in the mid 1960s; those implants remained successfully osteointegrated for 40 years until the patient's death (13). Since the 1980's, dental implant technology has benefited tremendously from improved manufacturing processes that allow for more aggressive fixture threading, surface texturing, and multiple length and dimension options (14). Processed bone grafting materials have also become readily accessible. In 2007, recombinant human BMP-2 was FDA approved for sinus augmentation and localized alveolar ridge augmentation. 3-dimentional preoperative scans are now the standard of care for implant planning, and surgical navigation based off the registration of these scans is becoming more widespread (15). As the technology improves, there is also a thought that robot assisted implant surgery will make the processes fully automated, delivering optimal precision (16).

\section{Craniofacial and orthognathic surgery}

Two prominent and contemporary maxillofacial surgeons laid the foundation for many of the techniques that are currently used today for treating craniofacial anomalies: Paul Tessier, the father of craniofacial surgery, and Hugo Obwegeser, the father of orthognathic surgery. Paul Tessier trained in maxillofacial surgery and was the founding member of the European Association of Oral and Maxillofacial Surgeons. He devoted the lion share of his efforts to the treatment of congenital anomalies, and 
pioneered several trans and subcranial approaches to treat craniofacial dysostosis. He is credited with bridging the fields of neurosurgery, ophthalmology, and craniofacial surgery. Importantly, he documented his surgical cases and left extremely detailed accounts and illustrations so that other surgeons could reproduce his work (17). Hugo Obwegeser, educated in both medicine and dentistry, spent time under Sir Harold Gillies in his early years similar to Paul Tessier. Whereas Paul Tessier focused on the manipulation of the upper and middle facial thirds, Obwegeser focused on the middle and lower facial thirds. Obwegeser conceived the original sagittal split osteotomy for mandibular repositioning. Modifications by Dal Pont and Hunsuck to his original plan have given us the modern sagittal split osteotomy design. Obwegeser also was the first surgeon to successfully mobilize the maxilla via the LeFort I osteotomy. His landmark conference in 1966 at Walter Reed Medical Center inspired United States OMS to integrate orthognathic surgery into their practice and started the surge of orthognathic procedures that United States OMS were uniquely skilled and qualified to perform.

Distraction osteogenesis has been attempted for limb lengthening procedures since the $14 \mathrm{ht}$ century, however the first report of distraction osteogenesis in the maxillofacial region appeared in 1927. Before Obwegeser designed the sagittal split, Varaztad H. Kazanjian, an oral surgeon by training, performed the first successful distraction procedure using bilateral L-shaped osteotomies attached a wire hook on the mandibular symphysis. Until the 1980s distraction was rarely performed given the inadequacy of distraction appliances and osseous fixation. In 1989, McCarthy was the first surgeon to utilize extraoral distraction on a human mandible. Early unidirectional distractors eventually gave way to the bidirectional distractors created by Molina and OrtizMonasterio (18). The internal low-profile distractors that are currently used today were only made possible by the advancements in materials engineering.

Although the principles remain unchanged, there have been modern advances to the planning and execution of the surgeries. Virtual surgical planning allows for greater outcome precision and has drastically reduced the time taken to plan craniofacial and orthognathic cases. The use of cutting guides has also allowed surgeons to perform bony cuts, such as the inverted-L and other unconventional osteotomies, entirely intraorally (19). Computer tomography data allow surgeons to plan the locations of their fixation screws and control the vectors of maxillofacial distraction.

Although anatomy does not dictate scope, the temporomandibular joint (TMJ) is almost exclusively treated by dental and OMS providers. Related to craniofacial surgery, Pruzansky and Kaban have contributed a widely popular mandibular/TMJ classification for hemifacial microsomia based on their extensive experience with the condition. With respect to surgical management of temporomandibular disorders, OMS in the 1980s were at the forefront of creating functional and durable temporomandibular joint prostheses. Unfortunately, the history of TMJ and component prostheses is stained by the failure of Teflon/Proplast materials (20). However, these failures coupled with advances in engineering and material science have guided the modern and reliable stock and custom joint options that have a purported shelf life of greater than 20 years. For the correction of internal derangements, endoscopic surgery and TMJ arthroscopy were pioneered by Joseph McCain. As more OMS are becoming facile with open approaches, their treatments are becoming more minimally invasive.

\section{Pathology}

In the United States OMS community there is currently a resurgence of interest in the management of oral and maxillofacial malignancy. In the late middle $20^{\text {th }}$ century, the introduction of orthognathic surgery largely distracted the specialty from pursuing expertise in oral oncology as was common in European OMS. Eric Dierks notes 3 early OMS surgeons who were able to maintain robust clinical practices in oral cancer surgery, however their legacy was relatively short lived (21). In the 1990s, a handful of national and international head and neck surgeons (Eric Dierks, Robert Marx, Joseph Helman, Robert Ord), who maintained professional allegiance to OMS, established training programs that ultimately led to the modern head and neck OMS surgical subspecialty (22).

A variety of pathologic conditions have fallen under the purview of OMS, and in response our specialty has developed novel solutions. With the increased use of head and neck radiotherapy, osteonecrosis became a diagnosis that OMS have grown familiar with. Marx in 1983 developed his ' $3 \mathrm{H}$ theory' for the pathogenesis of osteonecrosis and proposed a treatment protocol centered on hyperbaric oxygen. More recently, in 2004, Delanian and Lefaix proposed an alternative free radical hypothesis, and their group has shown good results 
using pentoxifylline and vitamin E (23). With Ruggerio's original report, our specialty was the first alert the medical community on bisphosphonate-related osteonecrosis of the jaw (BRONJ) (24), now generalized to medicationrelated osteonecrosis of the jaw (MRONJ). Currently there is ongoing prospective bench and translational research in the OMS community to identify and target precise pathways responsible for MRONJ.

In addition to the management of these benign, destructive conditions, OMS also pioneered novel reconstructive strategies. Given the routine availability of in-office computer tomography and 3-dimentional printing, OMS are able to able to perform in-house planning of complex reconstructions (25). Hirsh and colleagues first published their experience with 'jaw in a day' or immediate free fibula, dental implant, and dental prosthesis reconstruction (26). OMS are now routinely performing this procedure with greater precision using virtual surgical planning, and the vertical integration of resection to reconstruction remains the calling card of head and neck trained OMS. As another step toward restoring pre-morbid status in maxillofacial surgery, a select group of OMS centers are also offering single-staged nerve reconstruction for large ablative cases (27). The success rates with these inferior alveolar, lingual, and infraorbital nerve grafts approached $90 \%$ in cases of immediate repair $(28,29)$.

In conclusion, the works of many exceptional individuals have allowed our specialty to grow both in scope and in quality of care. We anticipate that the next wave of innovation will likely include robotic surgery (30) as well as machine learning to optimized geometries for bony reconstruction and precise implant placement. There is still much to explore in the realm of regenerative medicine, and the potential of autogenous platelet and serum growth factors is still to be determined. The guesswork of making blind osteotomies, free-handing dental implants, and estimating the position of free-floating segments are soon to be practices of the past. Although single surgeons working in silos were able to change the course of history, we believe that modern innovation requires collaboration as the problems become more advanced. OMS has a strong international presence and brotherhood. We are excited to see how the next generation of OMS surgeons will advance the specialty.

\section{Acknowledgments}

Funding: None.

\section{Footnote}

Provenance and Peer Review: This article was commissioned by the editorial office, Frontiers of Oral and Maxillofacial Medicine for the series "Clinical Outcomes and Innovations in Oral and Maxillofacial Surgery". The article has undergone external peer review.

Conflicts of Interest: All authors have completed the ICMJE uniform disclosure form (available at https://fomm. amegroups.com/article/view/10.21037/fomm-21-24/ coif). This series "Clinical Outcomes and Innovations in Oral and Maxillofacial Surgery" was commissioned by the editorial office without any funding or sponsorship. SKC served as the unpaid Guest Editor of the series and serves as an unpaid editorial board member of Frontiers of Oral and Maxillofacial Medicine. The authors have no other conflicts of interest to declare.

Ethical Statement: The authors are accountable for all aspects of the work in ensuring that questions related to the accuracy or integrity of any part of the work are appropriately investigated and resolved.

Open Access Statement: This is an Open Access article distributed in accordance with the Creative Commons Attribution-NonCommercial-NoDerivs 4.0 International License (CC BY-NC-ND 4.0), which permits the noncommercial replication and distribution of the article with the strict proviso that no changes or edits are made and the original work is properly cited (including links to both the formal publication through the relevant DOI and the license). See: https://creativecommons.org/licenses/by-nc-nd/4.0/.

\section{References}

1. Laskin DM. Oral and maxillofacial surgery: The mystery behind the history. J Oral Maxillofac Surg Med Pathol 2016;28:101-4.

2. Thomaidis V, Tsoucalas G, Fiska A. The Hippocratic Method for the Reduction of the Mandibular Dislocation, an Ancient Greek Procedure Still in Use in Maxillofacial Surgery. Acta Med Acad 2018;47:139-43.

3. Leatherbarrow H. Jourdain Anselme Brechillet. NYU Dental. 2017-2018. Available online: http://dental.nyu. edu/aboutus/rare-book-collection/anselme-brechillet. html. Accessed 01/30/2021 2021.

4. Lew D. A Historical Overview of AAOMS. AAOMS. 
2013. Available online: https://www.aaoms.org/images/ uploads/pdfs/historical_overview_aaoms.pdf. Accessed 01/30/2021 2021.

5. Hussey KD. British dental surgery and the First World War: the treatment of facial and jaw injuries from the battlefield to the home front. Br Dent J 2014;217:597-600.

6. Stelnicki EJ, Young VL, Francel T, et al. Vilray P. Blair, his surgical descendants, and their roles in plastic surgical development. Plast Reconstr Surg 1999;103:1990-2009.

7. Strother EA. Maxillofacial surgery in World War I: the role of the dentists and surgeons. J Oral Maxillofac Surg 2003;61:943-50.

8. Alpert B. The Evolution of Oral and Maxillofacial Surgery Over the Past 100+ Years-With Special Emphasis on the Role of Fluoride and the High-Speed Handpiece. J Oral Maxillofac Surg 2018;76:1611-5.

9. Morimoto K, Tsutsui Y, Ogura S, et al. Are Wireless Electronic Stethoscopes Useful for Respiratory Rate Monitoring During Intravenous Sedation? J Oral Maxillofac Surg 2018;76:70.e1-70.e5.

10. Pérez-García S, Lozano-Carrascal N, Ruiz-Roca JA, et al. Evaluation of endovenous sedation using BIS monitoring in dentistry. A systematic review. Med Oral Patol Oral Cir Bucal 2020;25:e439-48.

11. Christensen L, Svoboda L, Barclay J, et al. Outcomes With Moderate and Deep Sedation in an Oral and Maxillofacial Surgery Training Program. J Oral Maxillofac Surg 2019;77:2447-51.

12. Braidy HF, Singh P, Ziccardi VB. Safety of deep sedation in an urban oral and maxillofacial surgery training program. J Oral Maxillofac Surg 2011;69:2112-9.

13. Lewin T. Per-Ingvar Branemark, Dental Innovator, Dies at 85. The New York Times. 2014.

14. Chopra M, Vermani M, Swarup N, et al. Surface Treatment and Implant Bone Interface: A Systematic Literature Review. J Long Term Eff Med Implants 2020;30:283-94.

15. Miller RJ, Bier J. Surgical Navigation in Oral Implantology. Implant Dent 2006;15:41-7.

16. Wu Y, Wang F, Fan S, et al. Robotics in Dental Implantology. Oral Maxillofac Surg Clin North Am 2019;31:513-8.

17. Ghali MG, Srinivasan VM, Jea A, et al. Craniosynostosis surgery: the legacy of Paul Tessier. Neurosurg Focus 2014;36:E17.

18. Molina F, Ortiz Monasterio F. Mandibular elongation and remodeling by distraction: a farewell to major osteotomies. Plast Reconstr Surg 1995;96:825-40; discussion 41-2.
19. Franco PB, Farrell BB. Inverted Losteotomy: a new approach via intraoral access through the advances of virtual surgical planning and custom fixation. Oral Maxillofac Surg Cases 2016;2:1-9.

20. Lee KC, Eisig SB, Perrino MA. Foreign Body Giant Cell Reaction to a Proplast/Teflon Interpositional Implant: A Case Report and Literature Review. J Oral Maxillofac Surg 2018;76:1719-24.

21. Dierks EJ. Surgeons of oral cancer and leaders of a young specialty: The role of 3 oral and maxillofacial surgeons. J Oral Maxillofac Surg 2002;60:86-92.

22. Carlson ER. Oral/Head and Neck Oncologic and Reconstructive Surgery: The Creation of a Subspecialty in Oral and Maxillofacial Surgery. J Oral Maxillofac Surg 2018;76:237-47.

23. Delanian S, Lefaix JL. The radiation-induced fibroatrophic process: therapeutic perspective via the antioxidant pathway. Radiother Oncol 2004;73:119-31.

24. Ruggiero SL, Mehrotra B, Rosenberg TJ, et al. Osteonecrosis of the jaws associated with the use of bisphosphonates: a review of 63 cases. J Oral Maxillofac Surg 2004;62:527-34.

25. Moe J, Foss J, Herster R, et al. An In-House ComputerAided Design and Computer-Aided Manufacturing Workflow for Maxillofacial Free Flap Reconstruction is Associated With a Low Cost and High Accuracy. J Oral Maxillofac Surg 2021;79:227-36.

26. Levine JP, Bae JS, Soares M, et al. Jaw in a day: total maxillofacial reconstruction using digital technology. Plast Reconstr Surg 2013;131:1386-91.

27. Miloro M, Markiewicz MR. Virtual Surgical Planning for Inferior Alveolar Nerve Reconstruction. J Oral Maxillofac Surg 2017;75:2442-8.

28. Callahan N, Miloro M, Markiewicz MR. Immediate Reconstruction of the Infraorbital Nerve After Maxillectomy: Is it Feasible? J Oral Maxillofac Surg 2020;78:2300-5.

29. Miloro M, Zuniga JR. Does Immediate Inferior Alveolar Nerve Allograft Reconstruction Result in Functional Sensory Recovery in Pediatric Patients? J Oral Maxillofac Surg 2020;78:2073-9.

30. Hupp JR. Robotics and Oral-Maxillofacial Surgery. J Oral Maxillofac Surg 2020;78:493-5.

doi: 10.21037/fomm-21-24

Cite this article as: Lee KC, Chuang SK. History of innovations in oral and maxillofacial surgery. Front Oral Maxillofac Med 2022;4:6. 